\title{
Low Dosage and Long-Term Use of Cyclophosphamide Improve the Survival of Patients with Systemic Lupus Erythematosus
}

\section{Yoosuf Ali Ashraf Muhammad Hussenbocus}

Nanjing Drum Tower Hospital Clinical College of Nanjing Medical University https://orcid.org/00000002-3650-269X

\section{Ziyi Jin}

Nanjing Drum Tower Hospital: Nanjing University Medical School Affiliated Nanjing Drum Tower

Hospital

\section{Wenyou Pan}

Huaian First People's Hospital

\section{Lin Liu}

Xuzhou Central Hospital

\section{Min Wu}

Third Affiliated Hospital of Soochow University: Changzhou First People's Hospital

Huaixia Hu

Lianyungang Second People's Hospital

\section{Xiang Ding}

Lianyungang First People's Hospital

\section{Hua Wei}

Northern Jiangsu People's Hospital

\section{Yaohong Zou}

Wuxi People's Hospital

\section{Xian Qian}

Jiangsu Province Hospital of TCM

\section{Meimei Wang}

Southeast University Zhongda Hospital

\section{Jian Wu}

First Affiliated Hospital of Soochow University

\section{Juan Tao}

Wuxi TCM Hospital

Jun Tan

Zhenjiang First People's Hospital

\section{Zhanyun Da}


Affiliated Hospital of Nantong University

\section{Miaojia Zhang}

Jiangsu Province Hospital

\section{Jing Li}

Affiliated Hospital of Jiangsu University

\section{Xuebing Feng}

Nanjing Drum Tower Hospital: Nanjing University Medical School Affiliated Nanjing Drum Tower Hospital

\section{Lingyun Sun ( $\nabla$ lingyunsun@nju.edu.cn )}

Nanjing Drum Tower Hospital Clinical College of Nanjing Medical University https://orcid.org/00000002-8563-2036

\section{Research article}

Keywords: SLE, cyclophosphamide, mortality, dose-response

Posted Date: May 17th, 2021

DOl: https://doi.org/10.21203/rs.3.rs-504049/v1

License: (c) (1) This work is licensed under a Creative Commons Attribution 4.0 International License. Read Full License 


\section{Abstract}

Background: Cyclophosphamide (CTX) is an alkylating agent used in the treatment of systemic lupus erythematosus (SLE) for its potent immunosuppression effect. Many aspects of the use of CTX in SLE have been previously studied. However, its relation to mortality in SLE had rarely been mentioned. Thus we investigate the effect of cyclophosphamide on organ involvements and the overall and cause-specific mortality of SLE patients.

Methods: Information about CTX prescription were taken from medical records in the Jiangsu Lupus database that was set up to collect data from SLE patients since their first admission during 1999-2009 in Jiangsu province, China. Follow- up studies were carried out in 2010 and 2015 to check the survival status of the patients. Cox regression models were used to estimate hazard ratio (HR) and $95 \% \mathrm{Cl}$. Kaplan-Meier model was used to assess the effect of CTX on mortality between organ involvements and non-involvements.

Results: There were 221 deaths observed out of 2446 SLE patients. CTX users showed a lower mortality of SLE (8.4\%) with adjusted HR $(95 \% \mathrm{Cl})$ of $0.74(0.56-0.97)$, as compared to non-users. A decreased in overall mortality of SLE in low daily dosage of CTX, with adjusted HR $(95 \% \mathrm{Cl})$ of $0.54(0.36-0.81)$ and a significant dose-response pattern $(P=0.004)$ between overall mortality of SLE and long-term use of CTX with adjusted HR $(95 \% \mathrm{Cl}) 0.53(0.35-0.80)$ were observed. In cause-specific mortality analyses, protective effective of CTX was found to be insignificant. However, CTX could eliminate the differences in mortality between organ involvement and non-involvement, including renal, neuropsychiatric, cardiopulmonary, gastrointestinal and hematological involvements.

Conclusion: Low daily dosage and long-term use of CTX lowers the risk of overall mortality of SLE. CTX might improve the survival of patients with renal, neuropsychiatric, cardiopulmonary, gastrointestinal and hematological involvements.

\section{Background}

Systemic lupus erythematosus (SLE) is a chronic autoimmune disease that presents with a variety of manifestations, which can be mild to severe. It ranges from arthritis or the classic rash to internal organs involvement mostly the kidneys or central nervous system [1]. The treatment regime depends mostly on glucocorticoids, antimalarials and immunosuppressive agents [2]. This has vastly improved the prognosis of SLE with an increase in the global 10-year survival rates of patients from $63.2 \%$ in the 1950 s to $91.4 \%$ in 2010 [3]. Nevertheless there is significant high risk of mortality in SLE patients [4-6]. About one fourth of patients with diffuse proliferative lupus nephritis develop end stage renal failure. It is a great concern globally as it accounts for the majority of patient mortality in SLE [7]. In China, the infections are the leading cause of death in SLE over complications from kidney and central nervous system (CNS) [8]. 
Cyclophosphamide (CTX) is a chemotherapeutic agent that can improve outcomes in lupus nephritis (LN) $[9,10]$ and it has also been reported to have the therapeutic effects in both CNS and hematological involvement in lupus [11-13]. Lupus patients with thrombocytopenia have experienced improvement in platelet counts after treatment with CTX [13]. Several randomized controlled trials (RCTs) have demonstrated that treatments including CTX were superior to corticosteroid therapy alone in the long term due to their protective effect of renal function in patients with severe $\operatorname{LN}[9,10,14,15]$. Furthermore, it was reported that patients with manifestation of neuropsychiatric SLE had responded well with CTX treatment where they priory failed to other immunosuppressive therapy [11]. However, few studies have estimated the effect of CTX on survival of SLE. This study aims to investigate the association between treatment with CTX and overall as well as cause-specific mortality of SLE. Also we will assess what kind of the effect treated with CTX dosage and duration could prolong the survival of patients with SLE.

\section{Methods}

\section{Study design and participants}

In 2010, Jiangsu Lupus Collaborative Group in Jiangsu Province, China carried out a large-scale, multicentre retrospective study. All patients admitted for the first time across 26 centres with complete medical record between $1^{\text {st }}$ January 1999 and $31^{\text {st }}$ December 2009 were enlisted in the study. Patients who satisfied four or more classification criteria of SLE revised and updated by the American College of Rheumatology (ACR) were included [16]. Follow ups were conducted in 2010 and 2015 respectively to monitor the survival status of the patients. More details about the study design can be found in previous studies [17-19].

\section{Data collection and definition}

Following the approval of this study by the Institutional Review Board of Nanjing Drum Tower Hospital, a website (http://sys.91 sqs.net/sle/Index/index.html) was set up to gather and manage data from different hospitals. The data collected from all the medical records since the first hospitalization of SLE patients were demographic data, diagnostic information, medical history, organ involvements, laboratory tests, and type and dosage of medication.

The disease activity was measured by the SLE disease activity index 2000 (SLEDAI-2K), and the SLICC/ACR Damage Index (SDI) was used to evaluate damage to the organ system [20]. The laboratory variables which were defined as positive were: anti- dsDNA positive, antinuclear antibody positive, antiSm positive, complement $\mathrm{C} 3<0.8 \mathrm{~g} / \mathrm{l}$ and complement $\mathrm{C} 4<0.2 \mathrm{~g} / \mathrm{l}$. The immunosuppressant used included CTX, hydrochloroquine, leflunomide, azathioprine, methotrexate, mycophenolate mofetil, tripterygium, ciclosporin, tacrolimus and glucocorticoids.

The patients were grouped into CTX users and non-users based on the medical records. Patients who received CTX treatment in first and subsequent hospital admission and discharge were classified as longterm use. The other patients treated with CTX were defined as short-term use. The daily dosage of CTX 
administered was collected and in case a different dosage formula was used during the same treatment period, the mean daily dosage was calculated.

\section{Statistical analysis}

We used SAS version 9.3 (SAS Institute, Inc., Cary, NC, USA) to carry out statistical analyses. The median [interquartile range (IQR)] of continuous variables in a non-normal distribution between CTX users and non-users was compared using the Mann-Whitney $U$ test. We used the $\chi^{2}$ test to contrast the distribution of categorical variables. We calculated the hazard ratios (HRs) and corresponding $95 \%$ confidence intervals (Cls) and used Cox proportional hazards regression models to investigate the association between treatment of CTX and overall and cause specific mortality. Ordinal values of CTX usage for the different category of dosage and duration were used in the regression models to estimate $P$ value for trend. Stratified analyses were performed based on the following factors: gender, age at diagnosis, SLEDAl score at first admission, comorbidities, glucocorticoids and immunosuppressive medications, organ involvements and serology test. In addition we used the Kaplan-Meier model to compare the survival rate between organ involvement and non-involvement by CTX. Adjustments were made to the multivariate analysis models for potential confounding factors comprising of gender ( male $=1$, female $=$ 0 ), SLEDAI score at admission (continuous), comorbidities (yes = 1, no= 0 ), glucocorticoid treatment on admission (yes $=1$, no $=0$ ), and immunosuppressive treatment on admission (yes $=1$, no $=0$ ). $P$-values were two-sided, with $P$ less than 0.05 considered to be statistically significant.

\section{Results}

\section{Characteristics of SLE patients in the study}

Among the 2446 patients with SLE, 44.0\% (1077) were treated with CTX. The median (IQR) daily dose of CTX was 600 (400 - 800) $\mathrm{mg}$. The demographic and clinical characteristics of patients with SLE among CTX users and non-users are shown in table 1. The age of the participants is shown as median (IQR) of 31.6 (23.5 - 39.6) year-old for CTX users and 32.5 (23.6 - 41.1) year-old for non-users $(P<0.144)$. Majority of patients in the study were female and the proportion of CTX users were lower (85.0\%), compared with non-users (99.5\%) $(P=0.023)$. The SLEDAl score at admission is represented as median (IQR) of 14.0 (10.0 - 20.0) for CTX users and $13.0(9.0-18.0)$ for non-users $(P<0.001)$. There was a higher prevalence of comorbidities $(P<0.001)$ as well as cardiopulmonary $(P<0.001)$ and renal $(P<0.001)$ involvement in CTX users. CTX non-users were likely to be taking glucocorticoid $(P<0.001)$ and immunosuppressive medication $(P=0.031)$. There were no differences in CTX users and non-users in terms of positive autoantibodies of anti-dsDNA, anti-Sm and antinuclear antibodies, and abnormal complement of C3 and C4.

\section{Overall mortality}

There were 221 deaths (9.0\%) out of 2446 patients with SLE. The HR and $95 \% \mathrm{Cl}$ for overall mortality of SLE patients according to the usage of CTX including dosage and the length are shown in Table 2 . The 
mortality of SLE was $8.4 \%$ and $9.5 \%$ for CTX non-users and users, respectively. After adjustment was made to confounding factors, CTX users showed a lower mortality of SLE with adjusted HR $(95 \% \mathrm{Cl})$ of 0.74 (0.56 - 0.97), as compared to non-users. A decreased in overall mortality of SLE was found in lower daily dosage of CTX, with adjusted HR $(95 \% \mathrm{Cl})$ of $0.54(0.36-0.81)$, but with insignificant doseresponse pattern, $\left(P_{\text {trend }}=0.259\right)$. A significant dose-response pattern was observed between overall mortality of SLE and a long time of using CTX ( $\left.P_{\text {trend }}=0.004\right)$. The adjusted HR $(95 \% \mathrm{Cl})$ for long-term CTX use compared with non-users was 0.53 (0.35 - 0.80).

Further analyses were made to establish the association between CTX use and overall mortality of patients with SLE stratified by gender, age, SLEDAI score, comorbidities, organ involvements, serology test results and other medications. After adjustments were made to potential factors, we observed the associations between CTX use and mortality of patients with SLE were negative but turned to be insignificant in some subgroups. However, the protection of CTX on mortality of SLE were still observed for female, SLEDAI score ${ }^{3} 15$ group, with neuropsychiatric, renal and hematological involvement, low serum $\mathrm{C} 3$, but without comorbidities, mucocutaneous, gastrointestinal and immunosuppressive treatment (Table 3).

\section{Comparisons of patient's survival treated by CTX}

Figure 1 presents the comparisons of Kaplan-Meier survival curves by CTX use according to organ involvement. Increased mortality were significantly observed in SLE patients with neuropsychiatric $(P<$ 0.001), cardiopulmonary $(P<0.001)$, gastrointestinal $(P=0.025)$, renal $(P<0.001)$, and hematological $(P$ $=0.002)$ involvements among CTX non-users; however, those differences in mortality between organ involvement and non-involvement were eliminated among CTX users (all $P>0.10$ ). Moreover, high SLEDAI score ( $\geq 15)$ patients had higher mortality compared with low SLEDAI score (0-14) in CTX nonusers $(P<0.001)$ and users $(P=0.019)$, whereas such difference was weakened by CTX, but there were no differences for comorbidity, mucocutaneous and musculoskeletal involvement (Supplementary Figure S1).

\section{Cause specific mortality}

Among the 221 deceased patients, 70 (31.7\%) died from infection 36 (16.3\%), from neuropsychiatric disorders, 33 (14.9\%) from renal insufficiency, and 32 (14.5\%) from other organs involvements including cardiopulmonary, gastrointestinal and haematological involvement. Also, we observed 3 cases of deaths non-related to lupus in which two patients died from cancer and one patients committed suicide. Moreover, 47 patients died of unknown causes. We observed that the overall comparison of distribution of causes of death between CTX users and non-users was not significant $(P=0.892)$ (Table 4). Compared to non-users, the use of CTX decreased the mortality from infection, neuropsychiatric impairment, renal insufficiency, other organs involvements and unknown with adjusted $\mathrm{HR}(95 \% \mathrm{Cl})$ of 0.72 (0.45 - 1.18), 0.62 (0.31 - 1.24), 0.72 (0.36 - 1.46), 0.93 (0.45 - 1.89) and 0.87 (0.49 - 1.57), respectively, though they were no statistically significant (Table 4). 


\section{Discussion}

As far as we know, this is the first study that analyzed the association between CTX usage and overall as well as cause-specific mortality in patients with SLE. In this large multi-centre retrospective study, we found an inverse association between CTX therapy and overall mortality in SLE patients. Patients having renal, neuropsychiatric, cardiopulmonary, gastrointestinal and hematological involvement may improve survivability if they were CTX users.

Up to now, there is only one study reported the association between CTX use and mortality of SLE patients. In South Korea, 413 patients who were diagnosed with SLE across three tertiary rheumatology centers between 1992 and 2016 were retrospectively evaluated; it was noted that the use of CTX was not significantly associated with mortality of SLE patients in univariable Cox analyses [21]. However, this study has not performed multivariable analyses for CTX use, and further cause-specific mortality could not be examined due to the limited sample size. Moreover, previous studies reported that CTX improved renal but not overall survival [22]. Petri et al noted that clinical symptoms and survival of SLE patients with major organ injuries were significantly improved with pulsed high-dose CTX therapy [23]. In addition, there have been clinical studies that demonstrated the long-term efficacy of CTX in decreasing morbidity with no fatality cases in SLE patients [24].

In this present study, decreased overall mortality can be shown in patients taking low dosage of CTX (< $600 \mathrm{mg} / \mathrm{d}$ ), and a strong dose-response relationship was observed between decreased mortality of SLE and long-term CTX use. Previous studies have indicated that remission could be achieved with slow cumulative effect of CTX over time. Houssiau et al. showed in their study known as the "EURO-Lupus regimen" that low dose CTX provides a good alternative to high dose CTX as it yields good results clinically [9]. In their 10 years follow up, they found that low dose of CTX is beneficial in the long term as $70 \%$ of patients that took this regimen did not require any pulse of CTX following their initial therapy. However, they reported that there was no significant difference in mortality between the two groups treated with low dose and high dose of CTX respectively [10]. It should be noted that the patients' ethnicity was white European and most of them presented with disease of moderate severity. A recent network meta-analysis of 11 RCTs found that low dose CTX was the most efficient as induction therapy in LN and had the most effect in lowering the risk of serious infections [25]. Those evidences could support our findings that slow cumulative effect of CTX over time might improve survival of SLE patients.

Consistent with previous studies among Chinese population, infection, neuropsychiatric and renal insufficiency were among the most common cause of death in this study $[8,26]$. Although decreased mortality from specific causes of death were found to be associated with CTX users, we still do not have a sufficient sample size to observed significant associations. However, our findings showed that CTX has better protective effects against overall mortality in organ involvements such as neuropsychiatric, renal, cardiopulmonary, gastrointestinal and hematological involvements. Our findings were consistent with the 2019 update of the EULAR recommendations for management of SLE that CTX is used for organ- 
threatening disease, especially renal, cardiopulmonary or neuropsychiatric involvement, as well as 'rescue' therapy in patients with life-threatening or refractory disease such as thrombocytopenia [27].

The mechanism of action of CTX is not well understood in spite of its heavy usage as an immunomodulating agent in the treatment of SLE. CTX is a prodrug that requires bioactivation through multiple hepatic isoenzymes of cytochrome P450 (CYP2B and CYP3A), which metabolize it to 4-

hydroxycyclophosphamide [28]. The acylic tautomer of 4-hydroxycyclophosphamide is then cleaved nonenzymatically into phosphoramide mustard which is the therapeutic active compound and is supposed to cause alkylation and cross-linking of DNA, thereby inhibiting DNA replication which leads to cell death [29-31]. Some potential mechanisms from in vivo studies have been explained the protective effect of CTX on SLE. CTX impacts the immune system by depleting naïve, double negative (CD27 - IgD-) and preswitched memory B cells. Also, it causes a decrease in circulating plasmacytoid dendritic cells and in some subsets of effector T cells (CD8 + CD44 + CD62L-), which might subside inflammation [32]. Over time, CTX can inhibit plasmablast, which is a marker of disease activity [33]. CTX increases alpha-2macroglobulin, which has potent effect in decreasing leukocytes activity [34]. Studies performed in animals demonstrated the effect of CTX in impairing the phagocytic activity of macrophages and decreasing the leucocyte counts $[35,36]$. Those might explain the benefit of CTX in the treatment of chronic inflammatory diseases.

There are several limitations in our study. Firstly, as this was an observational study, we could not entirely get rid of unmeasured residual confounding, though adjustments were made in SLEDAI score, comorbidities and medications in the treatment. Secondly, due to the nature of our study being a retrospective design, information bias might be present. Since the use of CTX was estimated from hospital records, the duration and dosage of CTX might be overestimate because adherence was not taken into consideration. It would probably lead to an underestimation of the observed negative association toward null, making our observed association conservative. Thirdly, this study might not include patients with milder SLE. Nevertheless, this does not deter our goal of evaluating the protective effective of CTX use on mortality as the most severe end-stage of the disease spectrum generally has the greatest risk of complications as well as death. Fourthly, this study enrolled patients of Asian Chinese ethnicity and the results might not reflect in patients of African-American ethnicities as they are less responsive to CTX therapy [37]. Despite those limitations, this study has some benefits. Given that it is a large multicenter cohort study, we were able to perform both multivariate and stratified analysis to investigate the association between CTX and overall and specific causes of mortality. Moreover, the doseresponse relationships between duration and dosage of CTX and mortality in SLE were firstly estimated.

\section{Conclusion}

In conclusion, based on this retrospective cohort study, we can observed SLE patients treated with CTX have a decreased overall mortality, and is especially beneficial in low daily dosage and long-term use. CTX use may improve the survival of SLE patients with vital organ involvements, especially renal, neuropsychiatric, cardiopulmonary, gastrointestinal and hematological involvements. 


\section{Abbreviations}

SLE: systemic lupus erythematosus

CTX: cyclophosphamide

CNS: central nervous system

LN: lupus nephritis

RCTs: randomized controlled trials

ACR: American College of Rheumatology

SLEDAI-2K: Systemic Lupus Erythematosus Disease Activity Index 2000

SDI: SLICC/ACR Damage Index

IQR: inter quartile range (median)

HR: hazard ratio

\section{Declarations}

\section{Ethics approval and consent to participate}

This study was approved by the Institutional Review Board of Nanjing Drum Tower Hospital.

\section{Consent for publication}

Not applicable.

\section{Availability of data and materials}

The datasets in the present study are available from the corresponding author on reasonable request.

\section{Competing interests}

The authors declare that they have no competing interests.

\section{Funding}

This work was supported by the Major International (Regional) Joint Research Project (No.

81720108020), and Key Program of National Natural Science Foundation of China (No. 81930043).

\section{Author Contributions:}


Study conception and design: ZJ, XF, LS. Acquisition of data: FW, WP, LL, Min W, HH, XD, HW, YZ, XQ, Meimei W, JW, Juan T, Jun T, ZD, MZ, JL, LS. Analysis and drafting the article: TH, ZJ. Revising the article: XF, LS. All authors have finally approved the submitted version to be published.

\section{Acknowledgments}

The authors would like to thank all investigators and site staff of local hospitals who participated in this study and the Cinkate Corp for their assistance in helping built and manage our database website.

\section{References}

1. Lahita RG. The clinical presentation of systemic lupus erythematosus. In: Lahita RG, editor. Systemic lupus erythematosus. Academic press; 2011. p. 525-539.

2. Chan VS, Tsang HH, Tam RC, Lu L, Lau CS. B-cell-targeted therapies in systemic lupus erythematosus. Cell Mol Immunol. 2013;10:133-42.

3. Mak A, Cheung MW, Chiew HJ, Liu Y, Ho RC. Global trend of survival and damage of systemic lupus erythematosus: meta-analysis and meta-regression of observational studies from the 1950s to 2000s. Semin Arthritis Rheum. 2012;41:830-9.

4. Yen EY, Shaheen M, Woo JMP, Mercer N, Li N, McCurdy DK, et al. 46-year trends in systemic lupus erythematosus mortality in the United States, 1968 to 2013: a nationwide population-based study. Ann Intern Med. 2017;167:777-85.

5. Jorge AM, Lu N, Zhang Y, Rai SK, Choi HK. Unchanging premature mortality trends in systemic lupus erythematosus: a general population-based study (1999-2014). Rheumatology. 2018;57:337-44.

6. Tselios K, Gladman DD, Sheane BJ, Su J, Urowitz M. All-cause, cause-specific and age-specific standardised mortality ratios of patients with systemic lupus erythematosus in Ontario, Canada over 43 years (1971-2013). Ann Rheum Dis. 2019;78:802-6.

7. Yap DY, Tang CS, Ma MK, Lam MF, Chan TM. Survival analysis and causes of mortality in patients with lupus nephritis. Nephrol Dial Transplant. 2012;27:3248-54.

8. Mu L, Hao Y, Fan Y, Huang H, Yang X, Xie A, et al. Mortality and prognostic factors in Chinese patients with systemic lupus erythematosus. Lupus. 2018;27:1742-52.

9. Houssiau FA, Vasconcelos C, D'Cruz D, Sebastiani GD, Garrido Ed Ede R, Danieli MG, et al. Immunosuppressive therapy in lupus nephritis: the Euro-Lupus Nephritis Trial, a randomized trial of low-dose versus high-dose intravenous cyclophosphamide. Arthritis Rheum. 2002;46:2121-31.

10. Houssiau FA, Vasconcelos C, D'Cruz D, Sebastiani GD, de Ramon Garrido E, Danieli MG, et al. The 10year follow-up data of the Euro-Lupus Nephritis Trial comparing low-dose and high-dose intravenous cyclophosphamide. Ann Rheum Dis. 2010;69:61-4.

11. Fanouriakis A, Pamfil C, Sidiropoulos P, Damian L, Flestea A, Gusetu G, et al. Cyclophosphamide in combination with glucocorticoids for severe neuropsychiatric systemic lupus erythematosus: a retrospective, observational two-centre study. Lupus. 2016;25:627-36. 
12. Vasoo S, Thumboo J, Fong KY. Thrombotic thrombocytopenic purpura in systemic lupus erythematosus: disease activity and the use of cytotoxic drugs. Lupus. 2002;11:443-50.

13. Boumpas DT, Barez S, Klippel JH, Balow JE. Intermittent cyclophosphamide for the treatment of autoimmune thrombocytopenia in systemic lupus erythematosus. Ann Intern Med. 1990;112:674-7.

14. Gourley MF, Austin HA 3rd, Scott D, Yarboro CH, Vaughan EM, Muir J, et al. Methylprednisolone and cyclophosphamide, alone or in combination, in patients with lupus nephritis. A randomized, controlled trial. Ann Intern Med. 1996;125:549-57.

15. Boumpas DT, Austin HA 3rd, Vaughan EM, Klippel JH, Steinberg AD, Yarboro CH, et al. Controlled trial of pulse methylprednisolone versus two regimens of pulse cyclophosphamide in severe lupus nephritis. Lancet. 1992;340:741-5.

16. Hochberg MC. Updating the American College of Rheumatology revised criteria for the classification of systemic lupus erythematosus. Arthritis Rheum. 1997;40:1725.

17. Feng $X$, Zou Y, Pan W, Wang X, Wu M, Zhang M, et al. Prognostic indicators of hospitalized patients with systemic lupus erythematosus: a large retrospective multicenter study in China. J Rheumatol. 2011;38:1289-95.

18. Feng X, Pan W, Liu L, Wu M, Ding F, Hu H, et al. Prognosis for hospitalized patients with systemic lupus erythematosus in China: 5-year update of the Jiangsu cohort. PLoS One. 2016;11:e0168619.

19. Jin Z, Wang F, Pan W, Liu L, Wu M, Hu H, et al. Association of antimalarial drugs with decreased overall and cause specific mortality in systemic lupus erythematosus. Rheumatology. 2021;60:177483.

20. Touma Z, Urowitz MB, Gladman DD. Systemic lupus erythematosus disease activity index 2000 responder index-50 website. J Rheumatol. 2013;40:733.

21. Koh JH, Park EK, Lee HN, Kim Y, Kim GT, Suh YS, et al. Clinical characteristics and survival of 413 patients with systemic lupus erythematosus in southeastern areas of South Korea: a multicenter retrospective cohort study. Int J Rheum Dis. 2020;23:92-100.

22. Austin HA 3rd, Klippel JH, Balow JE, le Riche NG, Steinberg AD, Plotz PH, et al. Therapy of lupus nephritis. Controlled trial of prednisone and cytotoxic drugs. N Engl J Med. 1986;314:614-9.

23. Petri M. Systemic lupus erythematosus: 2006 update. J Clin Rheumatol. 2006;12:37-40.

24. Petri M, Jones RJ, Brodsky RA. High-dose cyclophosphamide without stem cell transplantation in systemic lupus erythematosus. Arthritis Rheum. 2003;48:166-73.

25. Bae SC, Lee YH. Comparative efficacy and safety of low-dose and high-dose cyclophosphamide as induction therapy for lupus nephritis: a network meta-analysis. Z Rheumatol. 2019;78:467-73.

26. Wu XY, Yang M, Xie YS, Xiao WG, Lin J, Zhou B, et al. Causes of death in hospitalized patients with systemic lupus erythematosus: a 10-year multicenter nationwide Chinese cohort. Clin rheumatol. 2019;38:107-15.

27. Fanouriakis A, Kostopoulou M, Alunno A, Aringer M, Bajema I, Boletis JN, et al. 2019 update of the EULAR recommendations for the management of systemic lupus erythematosus. Ann rheum Dis. 
2019;78:736-45.

28. Ekhart C, Doodeman VD, Rodenhuis S, Smits PH, Beijnen JH, Huitema AD. Influence of polymorphisms of drug metabolizing enzymes (CYP2B6, CYP2C9, CYP2C19, CYP3A4, CYP3A5, GSTA1, GSTP1, ALDH1A1 and ALDH3A1) on the pharmacokinetics of cyclophosphamide and 4hydroxycyclophosphamide. Pharmacogenet Genomics. 2008;18:515-23.

29. Petrillo SK, Desmeules P, Truong TQ, Devine PJ. Detection of DNA damage in oocytes of small ovarian follicles following phosphoramide mustard exposures of cultured rodent ovaries in vitro. Toxicol Appl Pharmacol. 2011;253:94-102.

30. Madden JA, Hoyer PB, Devine PJ, Keating AF. Involvement of a volatile metabolite during phosphoramide mustard-induced ovotoxicity. Toxicol Appl Pharmacol. 2014;277:1-7.

31. Ganesan S, Keating AF. Phosphoramide mustard exposure induces DNA adduct formation and the DNA damage repair response in rat ovarian granulosa cells. Toxicol Appl Pharmacol. 2015;282:2528.

32. Fassbinder T, Saunders U, Mickholz E, Jung E, Becker H, Schlüter B, et al. Differential effects of cyclophosphamide and mycophenolate mofetil on cellular and serological parameters in patients with systemic lupus erythematosus. Arthritis Res Ther. 2015;17:92.

33. Dörner T, Jacobi AM, Lipsky PE. B cells in autoimmunity. Arthritis Res Ther. 2009;11:247.

34. Budovsky A, Sneir R, Bazarsky E, El-On J. Alpha 2 macroglobulin activity in rats infected with Typanosoma lewisi and treated with cyclophosphamide and its effect on the malignancy of the disease. J Vector Borne Dis. 2007;44:128-36.

35. Wang S, Huang S, Ye Q, Zeng X, Yu H, Qi D, et al. Prevention of cyclophosphamide-induced immunosuppression in mice with the antimicrobial peptide sublancin. J Immunol Res. 2018; doi: 10.1155/2018/4353580.

36. Charlie-Silva I, Conde G, Gomes JM, Johnny da Rosa Prado E, Fernandes DC, Cristina de Moraes A, et al. Cyclophosphamide modulated the foreign body inflammatory reaction in tilapia (Oreochromis niloticus). Fish Shellfish Immunol. 2020;107:230-7.

37. Dooley MA, Hogan S, Jennette C, Falk R. Cyclophosphamide therapy for lupus nephritis: poor renal survival in black Americans. Glomerular disease collaborative network. Kidney int. 1997;51:1188-95.

\section{Tables}

Table 1 Characteristics of study patients 


\begin{tabular}{|c|c|c|c|}
\hline & CTX use & & \\
\hline Variables & users & Nonusers & $P$ \\
\hline Total & 1077 & 1369 & \\
\hline Age (years) & $31.6(23.5-39.6)$ & $32.5(23.6-41.1)$ & 0.144 \\
\hline SLEDAl score on admission & $14.0(10.0,20.0)$ & $13.0(9.0,18.0)$ & $<0.001$ \\
\hline Initial dosage of CTX (mg/day) & $600.0(400.0,800.0)$ & - & \\
\hline Gender (female) & $990(85.0)$ & 1274(99.5) & 0.287 \\
\hline \multicolumn{4}{|l|}{ Comorbidities } \\
\hline All & $149(12.8)$ & 102(8.0) & $<0.001$ \\
\hline Diabetes & $41(3.8)$ & $43(3.1)$ & 0.369 \\
\hline Hypertension & $32(3.0)$ & $13(0.9)$ & $<0.001$ \\
\hline Secondary Sjogren's syndrome & $25(2.3)$ & $13(0.9)$ & 0.006 \\
\hline Pulmonary or upper respiratory infections & $27(2.5)$ & $10(0.7)$ & $<0.001$ \\
\hline Others & $37(3.4)$ & $31(2.3)$ & 0.080 \\
\hline \multicolumn{4}{|l|}{ Organ involvement } \\
\hline Mucocutaneous & $721(66.9)$ & $868(63.4)$ & 0.068 \\
\hline Neuropsychiatric & $79(7.3)$ & $72(5.3)$ & 0.034 \\
\hline Musculoskeletal & $567(52.6)$ & $768(56.1)$ & 0.089 \\
\hline Cardiopulmonary & $268(24.9)$ & $255(18.6)$ & $<0.001$ \\
\hline Gastrointestinal & $59(5.5)$ & $59(4.3)$ & 0.181 \\
\hline Ocular & $6(0.6)$ & $5(0.4)$ & 0.481 \\
\hline Renal & $706(65.6)$ & $560(40.9)$ & $<0.001$ \\
\hline Hematological & $496(46.1)$ & $654(47.8)$ & 0.398 \\
\hline \multicolumn{4}{|l|}{ Positive autoantibodies } \\
\hline Anti-dsDNA & $593(64.9)$ & $725(62.9)$ & 0.347 \\
\hline Antinuclear antibody & $936(93.6)$ & 1192(93.4) & 0.860 \\
\hline Anti-Sm & $329(34.7)$ & 399(33.3) & 0.505 \\
\hline
\end{tabular}




\section{Abnormal complement}

\begin{tabular}{|llll|}
\hline C3 & $714(74.8)$ & $852(72.3)$ & 0.205 \\
\hline C4 & $473(64.6)$ & $687(65.1)$ & 0.848 \\
\hline Medications & & & \\
\hline Glucocorticoids & $1033(88.7)$ & $1237(96.6)$ & $<0.001$ \\
\hline Immunosuppressive & $535(45.9)$ & $740(57.8)$ & 0.031 \\
\hline
\end{tabular}

Table 2 Risk of death according to CTX use in patients with SLE

\begin{tabular}{|lllll|}
\hline Variables & $\begin{array}{l}\text { All } \\
\text { No2446 } \\
\text { No.(\%) }\end{array}$ & $\begin{array}{l}\text { Death } \\
\text { No221 } \\
\text { No.(\%) }\end{array}$ & HR(95\%Cl) & $\begin{array}{l}\text { Adjusted } \\
\text { HR(95\%Cl })^{\text {a }}\end{array}$ \\
\hline CTX use & & & & \\
\hline No & $1369(56.0)$ & $130(58.8)$ & 1.00 & 1.00 \\
\hline Yes & $1077(44.0)$ & $91(41.2)$ & $0.86(0.66-1.12)$ & $0.74(0.56-0.97)$ \\
\hline Initial dosage & & & & \\
\hline No & $1369(56.0)$ & $130(58.8)$ & 1.00 & 1.00 \\
\hline$<600$ mg/d & $456(18.6)$ & $32(14.5)$ & $0.67(0.46-0.99)$ & $0.54(0.36-0.81)$ \\
\hline$\geq 600$ mg/d & $621(25.4)$ & $59(26.7)$ & $1.01(0.74-1.37)$ & $0.90(0.66-1.23)$ \\
\hline$P$ for trend & & & 0.735 & 0.259 \\
\hline The length of use & & & & 1.00 \\
\hline No & $1369(56.0)$ & $130(58.8)$ & 1.00 & $0.89(0.65-1.21)$ \\
\hline Short-term use & $658(26.9)$ & $62(28.1)$ & $1.02(0.75-1.38)$ & $0.53(0.35-0.80)$ \\
\hline Long-term use & $419(17.1)$ & $29(13.1)$ & $0.64(0.42-0.95)$ & 0.004 \\
\hline$P$ for trend & & & 0.059 & \\
\hline
\end{tabular}

${ }^{\text {a }}$ Adjusted for sex (male $=1$, female $=0$ ), age (continuous), SLEDAl score on admission (continuous), comorbidities (yes $=1, \mathrm{no}=0$ ), glucocorticoids treatment (yes $=1$, no $=0$ ), immunosuppressive treatment (yes $=1$, no $=0)$.

Table 3 Hazard ratios for mortality according to CTX use in subgroups of patients with SLE. 
Variables

Gender

Female

Male

Age (years)

$<30$

$\geq 30$

SLEDAl score at admission

0-14

$\geq 15$

Comorbidities

No

Yes

Mucocutaneous involvement

No

Yes

Neuropsychiatric involvement

No

Yes

Musculoskeletal involvement

No

Yes

Cardiopulmonary involvement

No

Yes

Gastrointestinal involvement
Nonusers Users

Death/All Death/All HR(95\% Cl) Adjusted

$\mathrm{HR}(95 \% \mathrm{Cl})^{\mathrm{a}}$ 


\begin{tabular}{|c|c|c|c|c|}
\hline No & $120 / 1310$ & $85 / 1018$ & $0.88(0.66-1.16)$ & $0.75(0.56-1.00)$ \\
\hline Yes & $10 / 59$ & $6 / 59$ & $0.56(0.20-1.55)$ & $0.61(0.21-1.82)$ \\
\hline \multicolumn{5}{|c|}{ Ocular involvement } \\
\hline No & $130 / 1364$ & $89 / 1071$ & $0.84(0.64-1.10)$ & $0.72(0.55-0.95)$ \\
\hline Yes & $0 / 5$ & $2 / 6$ & - & - \\
\hline \multicolumn{5}{|c|}{ Renal involvement } \\
\hline No & $55 / 809$ & $27 / 371$ & $1.07(0.68-1.70)$ & $0.90(0.56-1.45)$ \\
\hline Yes & $75 / 560$ & $64 / 706$ & $0.65(0.47-0.91)$ & $0.63(0.45-0.88)$ \\
\hline \multicolumn{5}{|c|}{ Hematological involvement } \\
\hline No & $53 / 715$ & $45 / 581$ & $1.04(0.70-1.54)$ & $0.98(0.65-1.48)$ \\
\hline Yes & $77 / 654$ & $46 / 496$ & $0.74(0.51-1.07)$ & $0.64(0.44-0.93)$ \\
\hline \multicolumn{5}{|c|}{ Anti-dsDNA antibody } \\
\hline Negative & $32 / 428$ & $28 / 321$ & $1.05(0.63-1.75)$ & $0.75(0.44-1.30)$ \\
\hline Positive & $75 / 725$ & $56 / 593$ & $0.88(0.62-1.25)$ & $0.82(0.58-1.17)$ \\
\hline \multicolumn{5}{|c|}{ Antinuclear antibody } \\
\hline Negative & $9 / 84$ & $5 / 64$ & $0.63(0.21-1.88)$ & $0.58(0.19-1.80)$ \\
\hline Positive & $101 / 1192$ & $82 / 936$ & $1.01(0.76-1.35)$ & $0.86(0.63-1.16)$ \\
\hline \multicolumn{5}{|c|}{ Anti-Sm antibody } \\
\hline Negative & $81 / 798$ & $61 / 619$ & $0.90(0.65-1.26)$ & $0.78(0.55-1.09)$ \\
\hline Positive & $25 / 399$ & $21 / 329$ & $1.02(0.57-1.83)$ & $0.86(0.47-1.56)$ \\
\hline \multicolumn{5}{|l|}{ C3 } \\
\hline Normal & $24 / 326$ & $22 / 241$ & $1.24(0.70-2.21)$ & $1.07(0.59-1.95)$ \\
\hline Abnormal & $80 / 852$ & $58 / 714$ & $0.80(0.57-1.12)$ & $0.70(0.50-1.00)$ \\
\hline \multicolumn{5}{|l|}{ C4 } \\
\hline Normal & $30 / 369$ & $20 / 259$ & $0.90(0.51-1.58)$ & $0.78(0.43-1.40)$ \\
\hline Abnormal & $59 / 687$ & $43 / 473$ & $0.99(0.67-1.46)$ & $0.85(0.57-1.27)$ \\
\hline \multicolumn{5}{|c|}{ Glucocorticoids treatment } \\
\hline No & $11 / 132$ & $2 / 44$ & $0.57(0.13-2.56)$ & $0.38(0.08-1.89)$ \\
\hline Yes & $119 / 1237$ & $89 / 1033$ & $0.87(0.66-1.14)$ & $0.76(0.58-1.01)$ \\
\hline
\end{tabular}


Immunosuppressive treatment

\begin{tabular}{|lllll|} 
No & $88 / 629$ & $51 / 542$ & $0.62(0.44-0.87)$ & $0.57(0.40-0.82)$ \\
Yes & $42 / 740$ & $40 / 535$ & $1.34(0.87-2.06)$ & $1.20(0.77-1.88)$ \\
\hline
\end{tabular}

${ }^{\text {a }}$ Adjusted for sex (male $=1$, female $=0$ ), age (continuous), SLEDAl score at admission (continuous), comorbidities (yes $=1$, no $=0$ ), glucocorticoids treatment (yes $=1$, no $=0$ ), immunosuppressive treatment (yes $=1$, no $=0$ ), and the above adjusted variables would be excluded when it was the stratified variable.

Table 4 Association between CTX use and cause-specific mortality among patients with SLE

\begin{tabular}{|c|c|c|c|c|c|}
\hline \multicolumn{6}{|c|}{ CTX use ${ }^{c}$} \\
\hline Cause of death & $\begin{array}{l}\text { Total } \\
\mathrm{n}=221\end{array}$ & $\begin{array}{l}\text { Non- } \\
\text { user } \\
n=160\end{array}$ & $\begin{array}{l}\text { User } \\
\mathrm{n}=61\end{array}$ & $\mathrm{HR}(95 \% \mathrm{Cl})$ & $\begin{array}{l}\text { Adjusted } \\
\mathrm{HR}(95 \% \mathrm{Cl})^{\mathrm{d}}\end{array}$ \\
\hline Infection & 70(31.7) & $42(26.3)$ & $28(45.9)$ & $\begin{array}{l}0.81(0.50- \\
1.31)\end{array}$ & $\begin{array}{l}0.72(0.45- \\
1.18)\end{array}$ \\
\hline $\begin{array}{l}\text { Neuropsychiatric } \\
\text { involvement }\end{array}$ & $36(16.3)$ & $23(14.4)$ & $13(21.3)$ & $\begin{array}{l}0.69(0.35- \\
1.36)\end{array}$ & $\begin{array}{l}0.62(0.31- \\
1.24)\end{array}$ \\
\hline Renal insufficiency & $33(14.9)$ & 19(11.9) & $14(23.0)$ & $\begin{array}{l}0.90(0.45- \\
1.79)\end{array}$ & $\begin{array}{l}0.72(0.36- \\
1.46)\end{array}$ \\
\hline Other organs involvements ${ }^{a}$ & $32(14.5)$ & 17(10.6) & $15(24.6)$ & $\begin{array}{l}1.07(0.53- \\
2.14)\end{array}$ & $\begin{array}{l}0.93(0.45- \\
1.89)\end{array}$ \\
\hline None lupus related ${ }^{b}$ & $3(1.4)$ & $3(1.9)$ & $0(0.0)$ & - & - \\
\hline Unknown & $47(21.3)$ & $26(16.3)$ & $21(34.4)$ & $\begin{array}{l}0.99(0.55- \\
1.75)\end{array}$ & $\begin{array}{l}0.87(0.49- \\
1.57)\end{array}$ \\
\hline
\end{tabular}

a Other organs involvements included cardiopulmonary, gastrointestinal and hematologic involvements.

${ }^{\mathrm{b}}$ None lupus related deaths included 2 patients died from cancer and 1 patients died from suicide.

${ }^{c} P=0.892$ for the overall comparison of distribution of causes of death by Fisher test.

${ }^{\mathrm{d}}$ Adjusted for sex (male $=1$, female $=0$ ), age (continuous), SLEDAl score at admission (continuous), comorbidities (yes $=1$, no $=0$ ), glucocorticoids treatment (yes $=1$, no $=0$ ), immunosuppressive treatment (yes $=1$, no $=0)$.

\section{Figures}


A Survival Curves among CTX non-users

B Survival Curves among CTX users
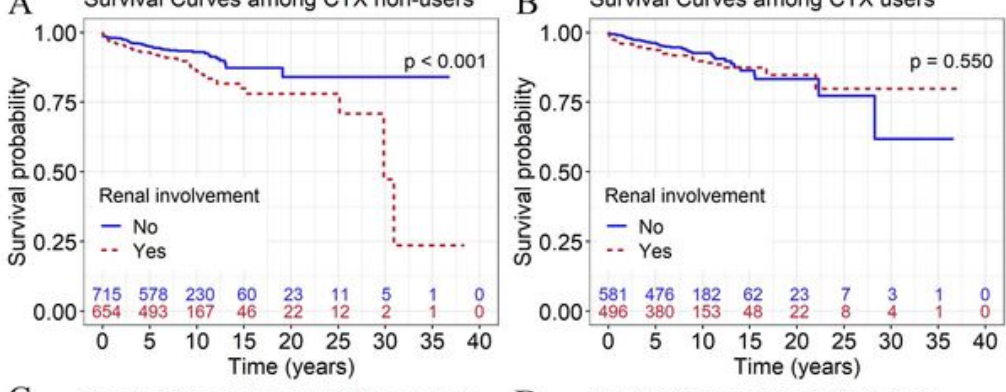

C Survival Curves among CTX non-users

D Survival Curves among CTX users
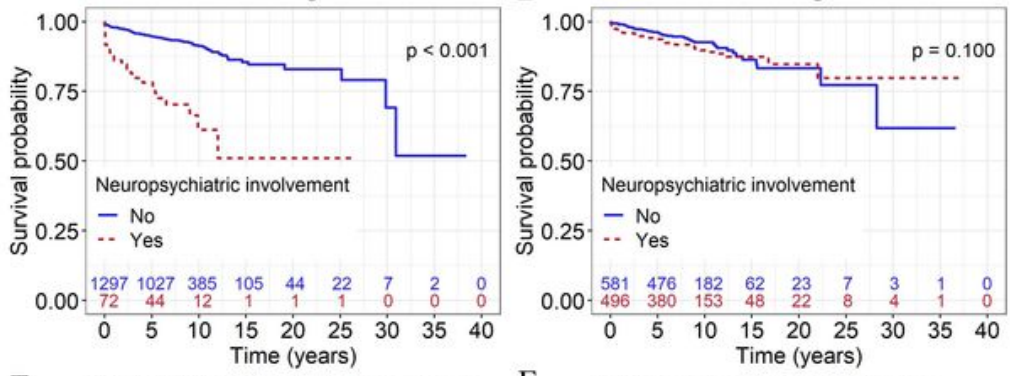

E Survival Curves among CTX non-users

F Survival Curves among CTX users
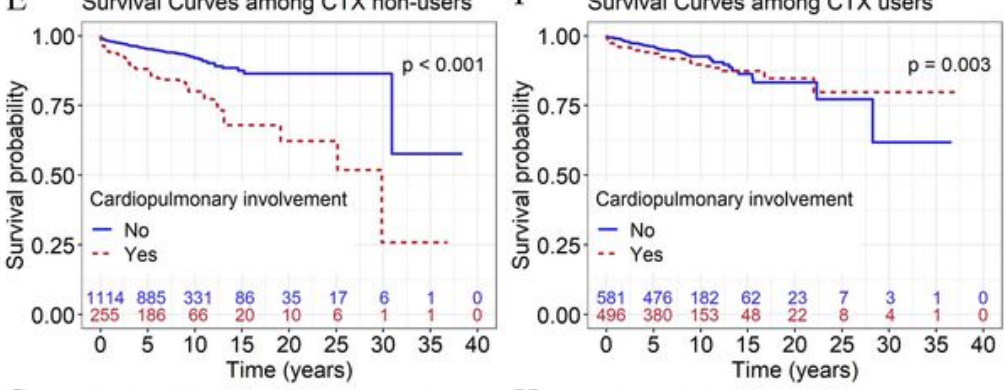

G Survival Curves among CTX non-users

$\mathrm{H}$ Survival Curves among CTX users
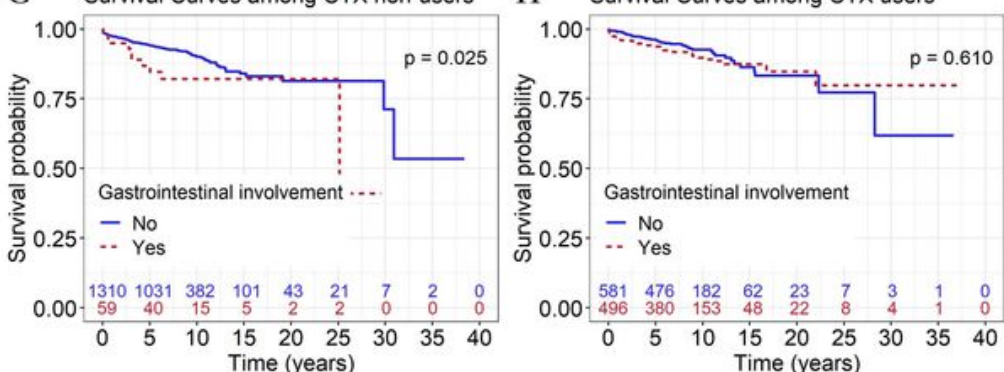

I Survival Curves among CTX non-users
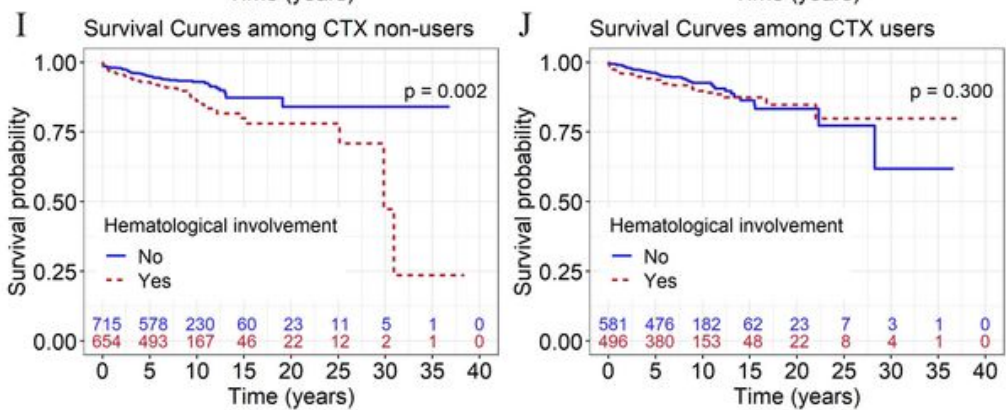

\section{Figure 1}

Comparisons of Kaplan-Meier survival curves by CTX use according to organ involvement including renal $(A$ and $B)$, neuropsychiatric $(C$ and $D)$, cardiopulmonary ( $E$ and $F)$, gastrointestinal ( $G$ and $H)$ and hematological (I and $\mathrm{J}$ ) involvement.

\section{Supplementary Files}


This is a list of supplementary files associated with this preprint. Click to download.

- SupplementaryFigureS1.jpg 